\title{
Corporate Social Responsibility and Culture: The case of the largest Greek Commercial Bank.
}

\author{
Dr. Ioannis G. Kinias \\ Adjunct Lecturer \\ Department of Business Administration \\ University of the Aegean, Mihalon 8, Chios, 82100 \\ Serafim Agrogiannis \\ PhD Candidate in Business Administration \\ Misum - Mistra Center for Sustainable Markets \\ Stockholm School of Economics \\ Eirini Bolla \\ Department of Business Administration \\ University of the Aegean \\ Mihalon 8, Chios, 82100
}

\begin{abstract}
Throughout the years, the banking sector has encountered many challenges and undergone numerous changes in an effort of keeping up with international expectations, regulatory initiatives and competitive pressures. On the one hand, banks have been diversifying their activities in pursuit of customising their services to industries' needs to increase their risk resilience and secure their marginal returns. On the other hand, they have been engaging in investments within the wider field of Corporate Social Responsibility (CSR). The underlying value proposition of this mandate rests upon facilitating and further strengthening mutually beneficial relationships with the society while recognising the delicate balance and preservation of the natural environment. In this direction, many banks in the last decades tried to ensure their image through investments in the field of culture. The present research explicates the manifestation and operationalisation of CSR through investment realised for cultural objectives as part of the social aspect business responsibility. As such, we shift attention towards practices applied worldwide by the banking sector with respect to museums. Furthermore, we abide by a single case study approach and investigate the business model of the Cultural Foundation of Piraeus Bank (CFPB) as a CSR practice. Piraeus Bank is the largest commercial bank in Greece and CFPB constitutes a unique paradigm worldwide, since the bank not only contributes to the establishment of the museum in line with the majority of other banking initiatives that witness support through sponsorships but it is also actively engaged in its ongoing operations. The network of CFPB includes currently nine thematic museums in several locations throughout Greece. In light of these, we present how CFPB aligns and realises its activities in terms of financing, relationships between its network of museum with local communities as well as the promotional strategies deployed. Finally, we also discuss on potential future research avenues and implication derived for both academia and practice.
\end{abstract}

Keywords: Corporate Social Responsibility (CSR), Banking Sector, Culture, Museums

\section{INTRODUCTION}

From the midst of the 20th century, CSR has grown significantly as a field of practical and academic attention and has been accompanied by a proliferating terminology (Garriga and Melé, 2004). Consequently, it presents itself as a main determinant of the financial sector (De la 
Cuesta et al., 2006) and has spurred interest across banks due to the industry's potential through innovative products and services. Against this backdrop, numerous managers have been responding to complying with expectations and requirements posed by the notion of CSR (Ogrizek, 2002). This is manifested often through organisational publications, participation in discussion forums and public relations efforts (Gore, 1998). This tendency is part of an ever increasing effort on behalf of banks to succeed in an extremely competitive environment by serving purposes of positive social impact. Dating back to the early 2000, a survey conducted by $\mathrm{PwC}$ in 2002 revealed that nearly 70 per cent of CEOs maintained that CSR was vital to their companies' profitability (Simms, 2002).

The idea of the so called "business case" is widespread in the writings of Heal (2004) who opines that banks could significantly benefit from applying even the most rudimentary notions of CSR in their human resource practices and their community involvement rationale. Despite the potential of benefits emanating from CSR, there is a great variety in both depth and breadth of engagement. In the study of Gray et al. (1995a,b) referring to United Kingdom's context, it was found that reporting practices of banks were relevantly widespread. In the Irish case, Douglas et al. (2004) asserted that the country's banking sector was falling behind in comparison with leading European banks in terms of quality and quantity of disclosure. In Singapore, Tsang (1998) stated that the corporate social reporting of the banking sector was relatively low. Following this line of reasoning, another research by Halabi (2006) found that Australian banks were amongst the highest performing companies in disclosing environmental and social information. Last but not least, Nikolaou (2007) demonstrated that Greek banks disclose environmental information in term of accountability and an effort of securing a qualitative environmental performance framework. Apart from these, empirical validation also pertains to banks applying both a social perspective in their operations through immediate engagement such as philanthropy and social community strengthening as well as creating specific foundations for carrying out context specific social activities (Imam, 2000). The overarching areas of CSR engagement for banks are eloquently delineated by Quintas (2000) who divide them into principles and practices of good governance (1), the social and environmental dimension of internal and external stakeholder relationships (2), the social focus of financial activity through impact investment (3) and social works (4).

McWilliams et al. (2006) states that CSR is conducive to stabilising an organisation and securing its operational performance. Indicative is the case of both Lehman Brothers and Bear, Sterns \& Co. Inc who were considered amongst the most respected, prestigious and enduring banks (Norton, 2011) and resulted in collapsing due to poor reporting and misleading users on their financial strengths (Jones, 2011a). This case is reminiscent of the fact that economic behaviour is dependent on the community's beliefs (Romer, 1984) forming the main motivational mechanism for market participants (Kim and Venkatachalam 2011, Hong and Kacperczyk 2008). It becomes therefore apparent that CSR engagement representing a wellestablished system of socially endorsed behaviour (Jones 2011b, Jahdi and Acikdilli 2009, Vanhamme and Grobben 2009) is imperative for the banking sector's survival. Graafland and van de Ven (2011) support that for banks CSR entails increased professionalism, stronger focus and compliance on codes of ethics, verification of employee capabilities as well as transparency, stakeholder response and collaboration with social institutions.

The Equator Principles (EPs, 2013) is a risk management framework, adopted by financial institutions, for determining, assessing and managing environmental and social risk in projects and is primarily intended to provide a minimum standard for due diligence to support responsible risk decision- making. This tool try to connect the environmental and social risk 
with financial plans. In 2009, 68 financial foundations in 28 countries have adopted these principles. SRI could be described as an investment discipline considering environmental, social and governance perspectives in achieving simultaneously both financial returns and positive societal impact. It is indicative that by the year 2013, more than one out of every six dollars under professional management in the United States (approximately $\$ 6,57$ trillion) were invested according to SRI strategies (US SIF Foundation, 2014).

The idea for this tool is not new. Banks in America used SRI at first time in 1920s but it came known to everyone in 1990s by its success in stable growth. SRI is an investment strategy which combines the financial return with social goods. It is also a way for banks to improve their extra-financial criteria according to the decision process concerning their portfolio. Through this practice, banks actually act as institutional investors. And this is especially helpful in trying not to sidestep the indispensable necessity of the tow-folded aim that banks through capital investments should serve.

There is growing evidence that banks as institutional investors are keen on adopting extrafinancial goals in their investment decisions and the issues of whether these investors perform better or worse receives central stage. The goal of SRI is to combine financial corporate performance with social good. When it comes down to achieving this goal in practice, there are various investment strategies to implement. Emanating from the close inquiry of academic and practitioner agendas, different investment strategies can be delineated. The literature review has identified three distinctive ways, namely social screening (1), engagement (2) and community involvement (3). These practices can be viewed under the heading also known as "SRI screening practices".

Screening connotes the practice of including or excluding companies from banks' portfolio with respect to certain environmental, governance and social criteria and is known as negative and positive screening (Domini, 1994). On the one hand, negative screening is the simplest form of socially responsible investment and materializes through the avoidance of investing in companies that are either considered as unethical (Sparkes and Cowton, 2004) or belonging to certain industries that are negatively perceived of by the publics due to their subject of business (e.g. tobacco, weapon manufacturing). On the other hand, positive screening favours those companies with above-average CSR performance and according to Renneboog et al. (2008) is often coupled with a best-in-class approach where investments are conducted to those companies exceeding a certain threshold of CSR performance and in accordance to predetermined standards (Schueth, 2003).

As a last socially responsible investment strategy we find community involvement or else as widely used with the term "community investing" (Glac, 2009). In its narrow conceptualisation it deals with supplying capital to the financially excluded. In its broader sense it equates with philanthropy, donations and sponsorships (Renneboog et al., 2008) and under this perspective is closer to philanthropic CSR that Porter and Kramer (2002) speak about. The differentiation between these two ends rests upon whether the donations of money and supportive services are made in light or not of an "expected return" even though this distinctive line is fading away due to the influence of associated value (Austin and Seitanidi, 2012) where indirect benefits such as reputation enhancement occur (Lii and Lee, 2012) that in turn could act as a market differentiation factor.

The case of CFPB is unique by both means of innovativeness and "newness" of approach even when compared with international best practices as well as the mix of responsible investment it depict with elements of engagement and community investment being prevalent. The main 
research area of the current paper falls within the premises of community involvement and in more specific we embrace the extended notion where sponsorship activities are also included. By doing so, we aim at overcoming the inherent drawback reverberating the majority of CSR research where researchers adopt an either or stance towards the issue of value and the related shorter- or longer- term perspectives. We aim at studying the implementation of CSR related investments of the banking industry from a social investment standpoint. In more specific, we make inquiries into Piraeus Bank Group and its CSR engagement through its Cultural Foundation supporting and running certain thematic museums. In doing so, we investigate how this set of practices affects the bank's organizational posture and its relationships with the respective local communities.

The rest of the study is organized as follows. Section two delineates the global overview with respect to the banking industry's practices in CSR community involvement through sponsorships. In the next section, we substantiate our arguments concerning the preferred methodology. The penultimate section presents the empirical results. The final section is a summary of both the study's conclusions as well as academic and business practice implications while also outlines potential avenues for future research attempts.

\section{GLOBAL OVERVIEW}

Nowadays, banks throughout the globe support social and environmental friendly actions. The main ethical-social approaches, supported by a distinctive business model in each case, are summarised in three categories. First, social responsibility is mainly tackled through the issuing of a CSR report where providing information about the bank's socially related actions is the only objective. This is also depicted by the phrase "what they say" meaning that it is a sole exercise of managerial discretion on behalf of the bank in deciding what and how to report. This in turn renders itself vulnerable against criticism of "greenwashing" and "public relations" in the bank's pursuit of presenting itself favourable in the eyes of investors and/or customers. This resembles more the effort of creating trust or else strengthening the reputation of being responsible. This constitutes a reactive approach in terms of value creation, hence the "old" business model paradigm remains unaltered and any CSR activity an in more specific social issues are treated from a risk management approach where securing reputation is the main objective. Second, is the case of social responsibility as a potential opportunity for improving the banking sector's bottom line. In this case, attention is given to "What they are" or else the establishment and commitment to the principles of social responsibility that will serve as the springboard for taking up different initiatives towards fulfilling their objectives. This approach disengages from the pure reactive character of the previous one and instead entails a degree of proactivity where social issues present themselves as potential future opportunities. Third, we discern a differentiated from traditional bank models approach where the organisation is further engaged into solving social problems and is recognised under the rubrics of "ethical banking". The difference between the second and the third approach rests upon the driving motivation. Whereas the second type of business model is justified through an instrumental approach, the third one establishes its case through a normatively attuned justification.

In the first and second streams, all actions from banks are taken in pursuit of economic efficiency. Ethical aspects and normative accounts constitute subjective additions, sociological restrictions, external obligations or valuable considerations attached and subordinated to economic rationality (Melé and Guillen, 2006). In the third view, normative accounts prevail over economic effectiveness and efficiency. However, this is not a matter of dichotomy, like a yes or no answer, but resembles more an issue of relevance and prioritization. Economic action 
in this manner is embedded in the prevailing social reality and unfolds within a normative context (Koos, 2012). As such, the banking sector's response to different social issues runs across a continuum from more reactive towards more proactive postures. This idea of different stages concerning the business model a bank adopts is inherent of the CSR concept itself. These modes of responsiveness aim at achieving either a shorter- or a longer- term advantage. In the former case, the prevailing perception is that social responsibility is an additional cost (Orlitzky, 2008) and manifests mainly as a reputation safeguard. In the latter case, reputation enhancement is again prevalent and served through strategies of cost leadership and differentiation (Kurucz et al., 2008).

This goes hand in glove with the importance that society gives to aspects apart from the pure economic reasoning. Emphasis is now placed on museum investments as a means of responding to social expectations and banks consider this engagement as promising for securing loyalty and increasing their customer base (O'Connor, 1998) since museums are the most attractive places for those visiting a country with more than half of the tourists visiting them (Richards, 1999). The main objective in this case is to leverage the far-reaching potential of museums to the benefit of the local society and economy. These types of museums are known as GLAMUR museums (Global Art Museums as Economic Re-Activators) and their role is to instigate a renewal of economic activity.

This new trend has been gaining momentum and many banks are now not only sponsoring but also managing museums. It is a form of financing amongst other such as government funding and endowments. From this perspective, museums have started to resemble more a form of social enterprise where banks are actively engaged as a means of securing seamless operation with the provision of the necessary financial and managerial capitals. In this manner, banks consider the main income sources of museums through tickets, souvenir shops and dedicated social intervention meetings as potential leverage points for their competitive advantage. Under this perspective, it seems rather safe to assume that this ever increasing trend of museums being deployed by banks as social enterprises that has been ongoing during the last twenty five years will continue at the same pace.

Sponsorship is the best way for museums to retain and further develop their existence and their offerings. To this end, banks appropriate large sums of money with the aim to create and expand museums' art collections while at the same time the treat these allocations as important social investments. This practice has been flourishing in the US from the early 1960s where David Rockfeller through Chase Manhattan Bank inserted the idea of "corporate art collection". This constitutes part of the wider attempts exerted by banks to exhibit their collections of art or fund and raise their own galleries as a means of attracting potentially new and wealthy customers while at the same time this effort was endowed with an egalitarian balm of fairness and proximity to the community and providing social value by raising the educational and satisfaction level of inhabitants. Following this line of reasoning, social status is granted to banks by serving as a potential differentiating factor whereas cultural and pedagogical aims are also fulfilled at the same time.

In this form of banks embracing a type of social enterprising they provide capital to the museum's ongoing operations. In essence they serve as capital provider let alone the incidents were they actively engage themselves in managing the museum itself. This has been a distinctive trend in Anglo-Saxon countries. An indicative example is the renovation of the London Museum back in 2007 that lasted for three years where it secured a full sponsorship of $£ 18$ million after its opening in 2010 from the oldest independent bank in the United Kingdom, namely C. Hoare \& Co. Bank. A variation of this practice is also reflected through targeted 
efforts to create museums or networks of museums with respect to the history of specific places and as well as scientific thematic exhibitions and cases of preserved environmental areas. The first recorded case of this variant belongs to the Bank of England back in 1964 when it established its own museum in pursuit of forming and educational partner by means of demonstrating the wider sociocultural and historical trends of the country. This movement was more than just money but it also connected back to the independent bank's operations through favourable terms of policy-bank relations.

Another illustrative example come from the Spanish context. The Spanish Caixa Bank founded a new generation of science museums as a realisation of an innovative idea dating back to 1990. One of the overall objective of the bank is to return money to the society from the added value derived from its financial activities. The main activity areas where the bank delves into as an explicit form of social contribution are research, science, environment and culture. Its museum is located in Barcelona in a building from 1909 fully renovated. This is the first interactive museum hosting animals and offering the opportunity to visitors of learning how to regard them. Special care has been given to the settings of the museum in order to make every visit as close as possible to resembling a walk in the forest. The social responsibility of Caixa Bank is also realised through the management the biggest charity institution in Spain and one of the biggest worldwide. More than $€ 100$ million are paid every year to cultural and environmental reasons. Furthermore, the bank collaborates with other museums such as the British museum and the museum of Louvre in order to host different exhibitions in its own premises. To continue with, in Sweden a network of banks offers to its customers credit cards with the ability to serve as entrance cards allowing them to visit museums. This unveils positive impacts for both the banks and the alliance museums. On the one hand banks strengthened their social responsibility image and the museums achieved an additional and secured input of profits.

In Germany, culture is considered an important aspect of social responsibility and consequently a fruitful field for banks to differentiate. In this case, instead of selling their own artworks, banks lease them under longer term agreements to museums. For example, Commerzbank assisted in this sense museums to organise popular exhibitions by hosting the bank's private art assets and the bank itself strengthened is image. Deutsche Guggenheim is a depictive case of a unique partnership between the bank and the Salomon R. Guggenheim institution with other museums in New York, Venice, Bilbao and Berlin. Both partnering organizations meaningfully support the management of Deutsche Guggenheim. Their main goal is not to increase the number of visitors but to promote modern art. However, it is acknowledge that the former might have rebound effects on the latter. Furthermore, Deutsche Bank owns one of the biggest art collections worldwide. Herbert Zapp was the first to adopt the idea of art works. At present, the bank has a collection of approximately 56000 art items and deploys the exhibition as a means of public relations as well as attracting new customers. Specifically, the bank has been implementing the program known as "Art Works" where its collection is made publicly available throughout its bank network to employees, customers and the public as well.

It becomes evident through the previous discussion, that there are cases worldwide indicating the increased uptake of this form of social enterprising from banks as a means of exhibiting CSR related activities. The cases elaborated have various forms and degrees of a reactive and/or proactive posture towards CSR. From simply using art collections and sponsorships as a means of attracting more customers while at the same time increasing cultural awareness and serving education reasons as an output of social value to more advance responses where 
the business model is significantly altered and introduces forms of partnerships through not only financial donations but through active support and engagement of the bank's established cultural foundations. However, there is still limited if not scant knowledge concerning motivations, value propositions and the perceived facilitators and obstacles that banks encounter in this specific form of social endeavour.

Aiming at increasing our understanding and unveiling the potential and particularities of this form of social responsibility that banks have started embarking on, we focus on the Greek context and in particular we use as our case reference the CFPB of the Piraeus Bank Group. This foundation is a non-profit institution sponsored and managed by the bank. The scope of CFPB's cultural activity covers the largest part of the bank's social responsibility practices. In this view, the foundation manages an organized network of nine thematic museums and the overarching goals is twofold: to save and promote the industrial technology of Greece. As such, it presents a unique case worldwide due to the nature of exhibitions and calls for elaborating on the particularities the foundation's role and practices.

\section{RESEARCH METHOD}

Due to the limited knowledge on this special case of social engagement that banks proceed with, we opted for a case study approach. This is particularly appropriate where limited research exists (Yin, 2003). This treatment also assists in overcoming the social desirability bias inherent in the study of the CSR topic (Eisenhardt and Graebner, 2007) and facilitate a deeper understanding towards preparing for research propositions and patterns of interactions (Eisenhardt, 1989). The interviewees were identified through purposeful sampling (Patton, 2002). They were selected on the justification of their degree of involvement with the particular social investment type of CSR action, their level of expertise as well as their hierarchical position and their length of employment in order to gain a rich account of the practice's implementation and evolution. To further elaborate on our choice, we abided by the measures outlined by Gibbert et al. (2008) to secure validity and reliability throughout the research process as well as alleviate any potential obstacles towards making connections with the applied theoretical lens and available literature. We catered for reliability through a case study protocol and a semi-structured interview guideline. External validity was considered through the collection of secondary data such as the foundation's and the Piraeus Bank Group's relevant reports on CSR issues. Construct validity was achieved through data triangulation by incorporating into the analysis internal guidelines and reports on social responsibility issues. Last but not least, internal validity was realised first by extracting our research focus from a thorough literature review and well supported concepts and second through interviewing the most knowledgeable informants and from different positions about the issue in question.

Our research aimed at investigating the relationship between the bank's operations and the cultural industry as witnessed through the CFPB as well as the effects posed on the organizational structure of the bank. The survey took play in 2016 and the following three executives form Piraeus Bank Group were interviewed:

- An executive from Piraeus Bank Group's department of CSR

- An executive from the CFPB

- The director of one thematic museum, namely the Marble Crafts Museum located in Tinos island

The interviews were recorder and subsequently transcribed and coded by the researchers individually where subsequent consensus was achieved through comparing the classifications of data categorization and key categories derived. 


\section{FINDINGS}

The nine thematic museum under the jurisdiction, supervision and function of CFPB are: the Silk Museum in Soufli(1), the Museum of Marble Crafts in Tinos(2), the Open Air Water Power Museum in Dimitsana(3), the Museum of Olive and Greek Olive Oil in Sparta $(4)$, the Museum of Industrial Olive-Olive Oil Production in Lesvos(5), the Mastic Museum in Chios(6), the Museum of Rooftile and Brickworks in $\operatorname{Volos}_{(7)}$, the Environment Museum of Stymphalia(8) and the Silversmithing Museum in Ioannina(9).

This expanding museums' network represents a unique, large scale cultural intervention as part of the wider social responsibility of Piraeus Bank Group. CFPB aims at creating and further developing an altered notion with respect to strengthening regional competencies and adding social value. The aforementioned museums are part of a wider aspiration of becoming the meeting places for local communities. In 2012, CFPB was awarded in the category "Dedidacated Services" from Europa Nostra for its activity and support in realising the preservation and further fusion into contemporary practices of the traditional and industrial heritage. In a proactive manner of decision making and operations CFPB has already been developing several actions for solidifying even more the potential social benefits through publications, research projects, scientific events as well as the establishment of a historical archive serving as a main reference point for those interested in the specificities of each regional museum and the cultural heritage targeted at each individual case. The operational model of this museums network includes administrative, accounting and marketing services in the foundation's premises. This model is facilitated and further supported through the extensive cooperation achieved and offered by the local communities as well as the various municipal and regional governmental authorities.

The major outcome reflecting the philosophy of CFPB and its future orientation could be described as "the preservation and showcasing of Greece's cultural heritage, with an emphasis on its artisanal and industrial technology as well as the connection of culture with the environment". The benefits of the local communities are important. For example, they accommodate the hundreds of thousands of visitors for the museums in question. This in turn acts in a revitalizing manner for the local economy whereas at the same time it further strengthens reputation and tourist brand name. The mission of CFPB is effectuated in a seamless interaction with the Hellenic Ministry of Culture, the regional self-governmental authorities, the local societies and a broader network of industry and academic experts on social/cultural and environmental issues.

All the interviewees highlighted that CFPB is "a voluntary non-profit foundation and its statues, its operational costs, including those of its museums, are covered by Piraeus Bank Group". This denotes an important contribution on behalf of CFPB since every profit and income achieved through sales, tickets etc. are totally reinvested in the museums in order to support their functioning needs and expand their operations. Additionally, CFPB "pursues the co-financing of certain projects through national and European programs". In continuation, CFPB also fosters collaboration networks with higher education institutions, research excellence centers, cultural institutions as well as with knowledgeable individuals and experts both within Greece and from abroad. All the interviewees presented their action plan and the framework supporting this endeavour that includes the recording and collection of Greek cultural heritage and identity, the preservation of the traditional, artisanal and industrial technology of Greece and the meaningful coupling between the cultural element and the relative advantage and idiosyncrasy of each region. 
The research also unveiled that the establishment and function of CFPB depicts a unique model of CSR with respect to culture worldwide. As has been also implied in the previous pages, banks often choose a less direct relationship with culture and their social commitment as usually explicated through sponsorships and grants. Even though the latter constitute a less time-binding relationships undoubtedly entailing less risk, CFPB is engaged proactively towards creating and appropriating value. Even though this approach might impose greater investment risk, it translates into increased social and financial value for the communities involved and also receives a business case notion for the bank itself even though profit is not the motivating driver for this venture. This is also highlighted by another finding according to which the museums support local societies through direct and indirect impacts. For example, they recruit and employ people from these communities as well as from a supply chain perspective where these museum supply their premises with local and regional resources and products. This in turn pays off in environmental terms as well since the transportation aspect of the supply function is reduced, hence low carbon management is also realised. Local production is further facilitated through exhibition events and Promotional marketing in cooperation with commercial chambers and associations of small and medium sixes producers. To elaborate even further on the derived benefits, the experience from CFPB proves that many of the museums' visitors become customers of Piraeus Bank Group, hence they actively contribute to its potential growth. This might be seen as a natural consequence since the brand name and reputation of the bank increase and the band is advertised in certain contexts within the individual museums. This bodes well with the argument that consumers need some credential of organisations being truly responsible instead of only preaching and pretending about adopting CSR practices. In our case, the bank strengthen its reputation and further differentiates from the competitors both in terms of products offered and in light of the processes applied for the operational support of each museum.

These benefits become more important and diversified if we consider the scope of positive impacts emanating from CFPB's actions and the museums themselves. Relevant activity is further extended and integrated to other sectors apart from the banking industry where knowledge exchange and mutual benefits serve as the collaboration roadmap. The opening and operation of a specialized library with open access, the implementation of various educational programmes with a focus on especially school-going ages and activities of participation in public dialogue to co-formulate social impact areas and cultural heritage are indicative of the multifaceted and beneficial nature of the CFPB's role.

Beyond doubt, the banking sector is characterised by a fully competitive environment, especially if one considers the current adverse economic environment prevalent in Greek reality as a result of the fierce crisis. This leads to the argument that many banks give priority to minimising on CSR costs and engage in those absolutely necessary activities that will foster their image and indirectly support their profitability. The case of Piraeus Bank Group has unveiled an innovative approach, one of its king even when considering international best practices through effectively managing normative justifications with instrumental calls.

\section{CONCLUSIONS}

The main objective of the current paper was to investigate the role of the banking sector in the field of cultural investments as a manifestation of CSR practices targeted towards creating social value. The preceding literature review revealed that the case of CFPB constitutes a unique case worldwide. Due to this gap in the literature and because of the uniqueness hence the extreme case this offered for empirical investigation, we dwelled on the practices adopted by CFPB. This expanded our research focus on both organisational levels within Piraeus Bank Group and the different interaction emanating from CFPB. As such, we aimed at understanding 
the processes underlying the respective initiative. In doing so, we explicate how a socially oriented CSR program from the bank fosters it business model transformation and how it is further supported through the CFPB and the different stakeholders. This work also presents that the so called business case of CSR is a combinatory outcome of both normative and instrumental aspirations, hence it provides a good example on managers on how to start embracing a delicate balance between exploration and exploitation activities and reminds us about the fact that often CSR outcomes might not be easily measured but they do entail benefits attributed to different target groups.

Although our research provides insight into this unique phenomenon of CFPB and its significance for Piraeus Bank Group and the related CSR posture, it comes not without limitations. While our approach was deemed appropriate for uncovering meaning and interrelations within this case, thus achieving increased internal and construct validity, it retains lower levels of external validity. However, due to the idiosyncratic nature of our case it seems difficult if not unavoidable to succeed in replicating and refining our propositions through a confirmatory large scale survey. Following this line of reasoning, another potential future avenue could rely on investigating those necessary capabilities needed on behalf of the foundation to successfully respond to the various activities it supports. Furthermore, insight could also be gained in conducting a longitudinal case study approach for CFPB at multiple consecutive points in time in order to further comprehend how the various mechanisms used between CFPB and the stakeholder groups support through time the development of those necessary capabilities. Third, it would be interesting to explore how the sustainability of this type of social purpose organization (i.e. CFPB) effectuates within its wider supply chain context. This is particularly important and answers the calls from Pagell and Shevchenko (2014) about studying supply chain settings where innovation is present and where implementing new organising practices answering the questions of how to become more sustainable are prominent. Last but not least, and in accordance with latest trends in business and supply chain research (e.g. Busse et al. 2016), attention could also be shifted towards the manner in which the foundation increases its supply chain visibility in tandem with the various community, state and other groups of stakeholders.

\section{References}

Austin, J. E. and Seitanidi, M. M., (2012), "Collaboration Value Creation: A Review of Partnering Between Nonprofits and Businesses: Part 1. Value Creation Spectrum and Collaboration Stages", Nonprofit and Voluntary Sector Quarterly, Vol. 41, No. 5, pp.: 726-758

Busse, C., Schleper, M., Weilenmann, J., and Wagner, S. M., (2016), 'Extending the Supply Chain Visibility Boundary: Utilizing Stakeholders for Identifying Supply Chain Sustainability Risks", August the 12th, International Journal of Physical Distribution and Logistics Management, forthcoming.

De la Cuesta, M., Munoz, M.J. and Fernandez, M.A. (2006), “Analysis of social performance in the Spanish financial industry through public data. a proposal”, Journal of Business Ethics, Vol. 69 No. 3, pp. 289-304.

Domini, A. K., (1994), "Ethical Investing", Addison-Wesley, Reading, MA.

Douglas, A., John, D. and Johnson, B. (2004), “Corporate social reporting in Irish financial institutions”, The TQM Magazine, Vol. 16 No. 6, pp. 387-9.

Eisenhardt, K. M. and Graebner, M. E., (2007), " Theory building from cases: Opportunities and challenges ", Academy of Management Journal, Vol. 50, No. 1, pp.: 25-32

Eisenhardt, K. M., (1989), " Building theories from a case study research ", Academy of Management Review, Vol. 14, No. 4, pp.: 532-550

EPs, (2013): "A financial industry benchmark for determining, assessing and managing environmental and social risk in projects", The Equator Principles III (2013). 
Garriga, E.M. and Mele, D. (2004), “Corporate social responsibility theories: mapping theterritory”, Journal of Business Ethics, Vol. 53, pp. 51-71

Gibbert, M., Ruigrok, W. and Wicki, B., (2008), "What passes as a rigorus case study? ", Strategic Management Jurnal, Vol. 29, No. 13, pp.: 1465-1474

Glac, K., (2009), “Understanding Socially Responsible Investing: The Effect of Decision Frames and Trade-Off Options", Journal of Business Ethics, Vol. 87, S. 1, pp.: 41-55

Gore, J.P. (1998), “FirstFed ad emphasizes community ties”, Bank Marketing, Vol. 30 No. 3, p. 13.

Graafland, J. J. and van de Ven, B. W., (2011)," The Credit Crisis and the Moral Responsibility of Professionals in Finance ", Journal of Business Ethics, Vol. 103, No. 4, pp.: 605-619

Gray, R.H., Kouhy, R. and Lavers, S. (1995a), “Corporate social and environmental reporting: a review of literature and a longitudinal study of UK disclosure”, Accounting, Auditing \& Accountability Journal, Vol. 8 No. 2, pp. 47-77.

Gray, R.H., Kouhy, R. and Lavers, S. (1995b), “Constructing a research database of social and environmental reporting by UK companies: a methodological note”, Accounting, Auditing \& Accountability Journal, Vol. 8 No. 2 , pp. 78-101.

Halabi, A.K., Kazi, A.U., Dang, V. and Samy, M. (2006), “Corporate social responsibility: how the top ten stack up”, Monash Business Review, Vol. 3 No. 2, pp. 20-4

Heal, G. (2004), “Corporate social responsibility - an economic and financial framework”, paper presented at the Annual Conference of the Monte Pasci Vita.

Hong, H. G., \& Kacperczyk, M. (2009), “The price of sin: The effects of social norms on markets”, Journal of Financial Economics, 93(1), 15-36.

Imam, S. (2000), “Corporate social performance reporting in Bangladesh”, Managerial Auditing Journal, Vol. 15 No. 3, pp. 133-41.

Jahdi, K. S., \& Acikdilli, G. (2009). "Marketing communications and corporate social responsibility (CSR): Marriage of convenience or shotgun wedding?”, Journal of Business Ethics, 88(1), 103-113.

Jones, M. J. (2011a). Creative accounting, fraud and international accounting scandals. Chichester, West Sussex, England: John Wiley \& Sons

Jones, M. J. (2011b). "The nature, use and impression management of graphs in social and environmental accounting”, Accounting Forum, 35(2), 75-89,

Kim, I., \& Venkatachalam, M. (2011), “Are sin stocks paying the price for accounting sins?” Journal of Accounting, Auditing \& Finance, 26(2), 415-442

Koos, S., (2012), " The Institutional Embeddedness of Social Responsibility: A Multilevel Analysis of Smaller Firms' Civic Engagement in Western Europe “, Socio-Economic Review, Vol. 10, pp.: 135-162

Kurucz, E., Colbert, B. and Wheeler, D., (2008), " The business case for corporate social responsibility ", in Crane, A., McWilliams, A., Matten, D., Moon, J. and Siegel, D. S., (eds.), The Oxford Handbook of Corporate Social Responsibility, Oxford: Oxford University Press, pp.: 83-112

Lii, Y-S. and Lee, M., (2012), 'Doing Right Leads to Doing Well: When the Type of CSR and Reputation Interact to Affect Consumer Evaluations of the Firm", Journal of Business Ethics, Vol. 105, No. 1, pp.: 69-81

McWilliams, A., Siegel, D. S. and Wright, P. M., (2006), 'Corporate Social Responsibility: Strategic Implications", Journal of Management Studies, Vol. 43, No. 1, pp.: 1-18

Melé, D. and Guillen, M., (2006), " The Intellectual Evolution of Strategic Management and its Relationship with Ethic and Responsibility ", Working Paper, No. 658, October, IESE Business School

Nikolaou, I.E. (2007), “Environmental accounting as a qualitative improvement of banks' service”, International Journal of Financial Service Management, Vol. 2 No. 2, pp. 133-5

Norton, S. (2011). Bank failures and accounting during the financial crisis of 2008-2009. In M. J. Jones (Ed.), Accounting, fraud and international accounting scandals (pp. 425-450), Chichester, West Sussex, England: John Wiley \& Sons.

O'Connor, J., (1998), "Popular Culture, Cultural Intermediaries and Urban Regeneration", in Hall, T. and Hubbard, P., (eds.), The Entrepreneurial City, Chichester: John Wiley \& Sons, pp.: 225-239

Ogrizek, M. (2002), "Forum paper: the effect of corporate social responsibility on the branding of financial services", 
Journal of Financial Services Marketing, Vol. 6 No. 3, pp. 215-28.

Orlitzky, M., (2008), " Corporate Social Performance and Financial Performance: A Research Synthesis ", in Crane, A., McWilliams, A., Matten, D., Moon, J. and Siegel, D. S., (eds.), The Oxford Handbook of Corporate Social Responsibility, Oxford: Oxford University Press, pp.: 113-134

Pagell, M. and Shevchenko, A., (2014), "Why research in sustainable supply chain management should have no future", Journal of Supply Chain Management, Vol. 50, No. 1, pp.: 44-55

Patton, M. Q., (2002), "Qualitative research and evaluation methods", Thousand Oaks, CA.: Sage Publications.

Porter, M. E. and Kramer, M., (2002), "The Competitive Advantage of Corporate Philanthropy", Harvard Business Review, December, Vol. 80, No. 9, pp.: 56-69

Quintas, J.R. (2006), “Las Cajas de Ahorros en el Ambito de la Responsabilidad Social Corporativa”, Papeles de Economia Espanola, Vol. 108, pp. 128-43

Renneboog, L., Horst, J. R. and Zhang, C., (2008), "Socially responsible investments: Institutional aspects, perfrormance, and investor behavior", Journal of Banking \& Finance, Vol. 32, No. 9, pp. 1723-1742

Richards, G., (1999), "European Cultural Tourism: Patterns and Prospects", in Dodd, D. and van Hemel, A.-M., (eds.), Planning European Cultural Tourism, Amsterdam: Boekman Foundation, pp.: 16-32.

Romer, D. (1984), "The theory of social custom: A modification and some extensions", Quarterly Journal of Economics, 99(4), 717-727

Schueth, S., (2003), "Socially responsible investing in the United States", Journal of Business Ethics, Vol. 43, No. 3, pp.: 189-194

Simms, J. (2002), “Business: corporate social responsibility - you know it makes sense”, Accountancy, Vol. 130 No. 11, pp. 48-50.

Sparkes, R. and Cowton, C. J., (2004), " The Maturing of Socially Responsible Investment: A Review of the Developing Link with Corporate Social Responsibility", Journal of Business Ethics, Vol. 52, No. 1, pp.: 45-57

Tsang, W.K.E. (1998), "A longitudinal study of corporate social reporting in Singapore: the case of the banking, food and beverages and hotel industries", Accounting, Auditing \& Accountability Journal, Vol. 11 No. 5, pp. 624-8

US SIF Foundation (2014): “Report on Sustainable and Responsible Investing Trends in the United States", US SIF Foundation.

Vanhamme, J., \& Grobben, B. (2009). "Too good to be true. The effectiveness of CSR history in countering negative publicity". Journal of Business Ethics, 85(2) 273-283. 